\title{
SISTEMA PARA APOIO NA PRODUÇÃO DE LAUDO DE PASSIVO AMBIENTAL EM RODOVIAS COM IMAGENS TERRESTRES TRIDIMENSIONAIS
}

\section{SYSTEM SUPPORT IN LIABILITIES OF ENVIRONMENTAL REPORT PRODUCTION IN ROAD WITH LAND THREE DIMENSIONAL IMAGES}

Valter Vinicius Situlino Wanderley'; Francisco Assis da Silva ${ }^{1}$; Danillo Roberto Pereira ${ }^{1}$; Ricardo Luiz Barbosa ${ }^{2}$; Rodrigo Bezerra de Araújo Gallis $^{3}$

\footnotetext{
${ }^{1}$ Faculdade de Informática - FIPP, Universidade do Oeste Paulista - Unoeste e-mail: valtervinicius87@yahoo.com.br, \{chico, danilopereira \}@unoeste.br

${ }^{2}$ Universidade Estadual Paulista - Unesp, Campus de Sorocaba e-mail: ricardo@intsol.com.br

${ }^{3}$ Universidade Federal de Uberlândia - UFU Campus Monte Carmelo e-mail: rodrigogallis@ig.ufu.br
}

RESUMO - A integração de tecnologias digitais vem criando novas opções de soluções para problemas já conhecidos. Imagens e mapas digitais auxiliam administradores na tomada de decisão e melhoram os padrões de qualidade e segurança nas rodovias. O mapeamento móvel vem incorporando avançadas tecnologias recentes, como as imagens tridimensionais para coletar dados, apresentando um grande potencial de informações que podem ser abstraídas da análise desses dados. Áreas atingidas devem ser identificadas e os impactos ambientais diretos e indiretos precisam ser avaliados, produzindo um diagnóstico ambiental do local do acidente e seu entorno, que auxilia o planejamento das ações. Este trabalho vem a contribuir com uma solução de software que reúne informações de campo, imagens fotográficas e tridimensionais, e geolocalização para o apoio na produção de laudos passivos ambientais de áreas que estão sujeitas às constantes intervenções humanas.

Palavras-chave: Laudo Passivo Ambiental; Imagens Tridimensionais; Mapeamento Móvel; LadyBug.

ABSTRACT - The integration of digital technology has created new options for solutions to known problems. Images and digital maps assist managers in decision making and improve the quality and safety standards on roads. The mobile mapping has incorporated recent advanced technologies such as three-dimensional images to collect data, presenting a great potential for information that can be abstracted from data analysis. Affected areas should be identified and the direct and indirect environmental impacts need to be evaluated, producing an environmental diagnostic of the accident site and its surroundings, which assists the planning of actions. This work is to contribute to a software solution that combines field information, photographs and three-

Recebido em: 23/06/2015 Revisado em: 08/07/2015 Aprovado em: 10/08/2015 dimensional images, and geolocation to support the production of environmental liabilities reports of areas that are subject to constant human intervention.

Keywords: Environmental Liability Report; Three-Dimensional Images; Mobile Mapping ; Ladybug. 


\section{INTRODUÇÃO}

O transporte de produtos dos setores químicos, petroquímico, de refino de petróleo, e outros produtos perigosos são realizados no Brasil, em sua maior parte, cerca de 70\%, por rodovias (ALVES; GONTIJO; JUNIOR, 2009).

Os acidentes com cargas perigosas são $40,5 \%$ do total dos acidentes ambientais atendidos entre 1978 e 2008 pela CETESB Companhia de Tecnologia de Saneamento Ambiental do Estado de São Paulo (CETESB, 2009) e foram provocados por transporte rodoviário de cargas perigosas. Estes acidentes podem causar diversos impactos ambientais, como por exemplo, contaminação do solo, de águas superficiais e subterrâneas, impactos à fauna e vegetação, agropecuária e também para à saúde.

As áreas e objetos atingidos (solos, vegetação, corpos hídricos etc.) devem ser identificados e os impactos ambientais diretos e indiretos avaliados. Também deve ser realizado o diagnóstico ambiental do local do acidente e seu entorno para auxiliar o planejamento das ações e gestão e a previsão de novos impactos ou, ainda, do comportamento dos impactos identificados. Estes procedimentos devem ser realizados em campo de forma emergencial, rapidamente (LONGHITANO, 2010).

Atualmente a área ambiental está em avanço, isso principalmente devido ao surgimento de legislação, profissionais técnicos e literatura especializada no assunto. Os avanços no tratamento ambiental de rodovias também estão relacionados à incorporação da variável ambiental na rotina de trabalho dos órgãos rodoviários, à maior fiscalização dos órgãos ambientais competentes, à difusão de manuais técnicos contendo instruções ambientais para projetos e obras rodoviárias, à avaliação econômica das medidas de controle ambiental e quantificação dos custos ambientais de projetos, da implantação, e da manutenção de rodovias e à progressiva implantação de programas de recuperação do passivo ambiental em diversas rodovias do país (COELHO, 2014).

Um acervo de imagens e mapas digitais auxilia os administradores para a tomada de decisão e melhora os padrões de qualidade e segurança nas rodovias. Particularmente, os Sistemas Móveis de Mapeamento (SMM) (TOTH, 1995; SILVA et al., 2001a; SILVA et al., 2001b; GALLIS et al., 2002; SILVA et al., 2003) desempenham um papel importante na coleta de dados para mapear rodovias e prover dados e imagens para um Sistema de Informação Geográfica (SIG) (GALLIS et al., 2000; GALLIS et al., 2013).

Os impactos ambientais significativos geralmente ocorrem na área de influência direta da rodovia que envolve as faixas de domínio da estrada e/ou as microbacias de 
drenagem, e é geralmente nessa área que aparecem os principais impactos ambientais (ex: erosões, desapropriações, segregação urbana, etc.). Os impactos ambientais cadastrados ao longo do segmento da rodovia compreendem o seu passivo ambiental, que foi gerado a partir da implantação da rodovia e de atividades antrópicas danosas ao corpo estradal, a faixa de domínio e a região lindeira. De acordo com a nova normativa do IBAMA (Instrução

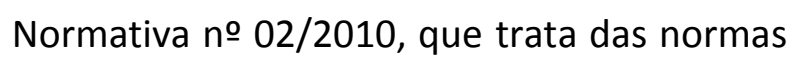
que serão aplicadas para a concessão de licença ambiental necessária para a regularização da malha rodoviária federal em operação), considera-se passivo ambiental rodoviário toda a ocorrência decorrente de falha de construção, conservação, restauração ou melhoramento da rodovia capaz de atuar como fator de dano ou degradação ambiental na faixa de domínio, ou fora desta, desde que comprovadamente originada nesta (RIBEIRO, 2010).

A Figura 1 mostra um exemplo de imagem 360 tomada para um inventário, onde foi percorrida uma estrada em um determinado trecho. Nesse trecho os passivos ambientais poderiam ser observados, e localizados por meio de coordenadas UTM (North, East), caracterizados e documentados por registros fotográficos. Esses elementos permitem a elaboração de Fichas de Caracterização de cada passivo ambiental. Um sistema de mapeamento móvel com imagens tridimensionais pode realizar este tipo de levantamento de modo rápido e preciso.

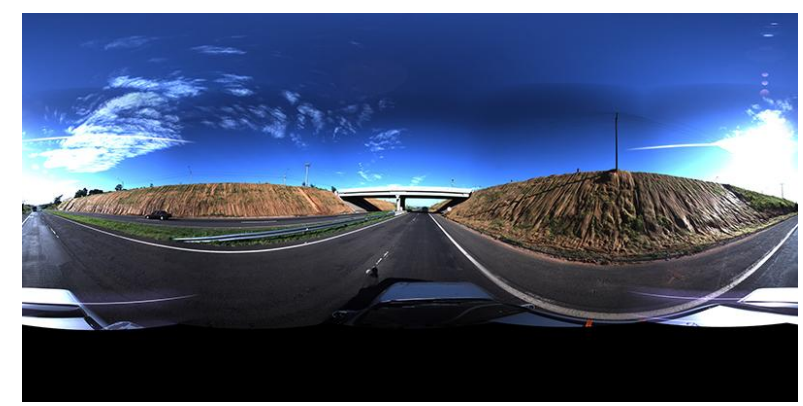

Figura 1. Exemplo de imagem 360 de um trecho de rodovia.

Neste cenário, a incorporação da variável ambiental no gerenciamento das rodovias pelos órgãos rodoviários é fundamental. Atualmente, devido à maior fiscalização dos órgãos ambientais competentes, à difusão de manuais técnicos contendo instruções ambientais para projetos e obras rodoviárias, à avaliação econômica e quantificação dos custos ambientais dos projetos de implantação e da manutenção de rodovias e à progressiva implantação de programas de recuperação do passivo ambiental em diversas rodovias do país, a concepção de um sistema de coleta de dados georreferenciados e de um sistema de gerenciamento integrado dessas informações torna-se essencial aos tomadores de decisões e planejadores modernos.

As áreas de influência dos impactos ambientais são as áreas em que podem ser 
observados os efeitos da rodovia. A área de influência indireta compreende a faixa em que os efeitos são sentidos de modo diluído ou indiretamente, geralmente, estes impactos são relacionados com os conflitos potenciais resultantes da ocupação e/ou apropriação inadequadas do espaço rural ou urbano, ou com a perturbação de usos consolidados da área. A área de influência direta geralmente envolve no mínimo as faixas de domínio da estrada e/ou as microbacias de drenagem, geralmente é nessa área que aparecem os principais impactos ambientais da rodovia (ex: erosões, desapropriações, segregação urbana etc.) Os impactos ambientais significativos geralmente ocorrem na área de influência direta da rodovia, que são onde o sistema de mapeamento móvel dotado de um sistema de coleta tridimensional pode trafegar (COELHO, 2014).

Os acidentes em rodovias, em geral apresentam impactos de pequena extensão em áreas (<10 ha). Como não é possível prever onde e quando ocorrerão acidentes e a avaliação de impactos destes tem caráter emergencial, as imagens de sensoriamento remoto para este fim devem ser dotadas de altíssima resolução espacial e necessitam ser obtidas em momentos determinados, sem possibilidade de planejamento prévio.

Atualmente, não há uma metodologia dominante no que tange a realização de levantamentos relacionados a passivos ambientais. Algumas empresas utilizam formulários onde os responsáveis pelos levantamentos preenchem campos relacionados à ocorrência e tiram fotos e coletam coordenadas dos locais envolvidos.

Este trabalho vem a contribuir com a implementação de uma solução computacional utilizando bancos de dados na Web, que possibilita produzir laudos de passivo ambiental e disponibilizar as feições georreferenciadas. Com equipamentos móveis, um usuário (engenheiro/administrador) pode, in loco, verificar ou atualizar informações. Os laudos passivos podem ser integrados com SIG's (Sistemas de Informações Geográficas) para auxiliar na tomada de decisão e também ser via Web, para possibilitar o compartilhamento com outros especialistas e gestores envolvidos.

As demais seções deste trabalho estão organizadas da seguinte maneira: na Seção 2 é detalhado o referencial teórico investigado para elucidar os conceitos teóricos usados neste trabalho; na Seção 3 é apresentada a metodologia para a implementação da solução computacional proposta; a Seção 4 apresenta os experimentos realizados e os resultados obtidos; por fim, a Seção 5 apresenta as considerações finais deste trabalho. 


\section{TRABALHOS RELACIONADOS}

Segundo Tinoco e Kraemer (2008) o passivo ambiental deve ser reconhecido nos relatos financeiros se é de ocorrência provável e pode ser razoavelmente estimado, existindo vários padrões de contingência que devem ser usados para caracterizar o que seria um evento de ocorrência provável. Se existir dificuldades para estimar seu valor deverá ser provisionado um valor estimável, registrando os detalhes dessa estimativa em notas explicativas. Ainda, de acordo com os autores, na mensuração do passivo devem-se levar em consideração os custos incrementais diretos que podem ocorrer com a reparação; os custos dos salários e encargos sociais aos trabalhadores vinculados ao processo de restauração ambiental; obrigações de controle após a reparação dos danos ambientais; e o progresso tecnológico à medida que seja provável que as autoridades públicas recomendem a utilização de novas tecnologias. De acordo com Tinoco (1994) na elaboração de um balanço ambiental, as principais dificuldades que se apresentam são a mensuração e a correta identificação dos ativos e passivos envolvidos, bem como o padrão de acumulação que possa facilitar a operacionalização do processo contábil.

De acordo com Johr (1994) a rapidez com que a legislação de proteção ao meio ambiente vem caminhando, implica, para as empresas, uma multiplicação de gastos com as adaptações sequenciais. Isso começaria a afetar a própria flexibilidade das operações, que teriam de ser repensadas e realocadas a cada mudança legal, exponenciando os custos. É por isso que, muitas vezes, fica mais econômico antecipar-se à lei do que segui-la a cada compasso. Uma atitude preventiva, portanto, estaria prevenindo a empresa não só sobre possíveis desastres presentes, mas, sobretudo protegendo-a contra inúmeros problemas futuros.

Segundo Almeida (2002) os princípios fundamentais da gestão ambiental são: incluir a gestão ambiental nas prioridades da empresa; estabelecer diálogo permanente com as partes interessadas, dentro e fora da empresa; identificar as leis e normas ambientais aplicáveis às atividades, produtos e serviços da empresa; comprometer-se a empregar práticas de proteção ambiental com clara definição de responsabilidades; estabelecer processo de aferição das metas de desempenho ambiental; oferecer continuamente os recursos financeiros e técnicos apropriados para alcance das metas e avaliação do desempenho ambiental; avaliar rotineiramente 0 desempenho ambiental da empresa em relação às leis, normas e regulamentos aplicáveis, objetivando o aperfeiçoamento contínuo; implementar programas permanentes de auditoria do sistema de gestão ambiental, 
para identificar oportunidades de aperfeiçoamento do próprio SGA e dos níveis de desempenho; harmonizar o SGA com outros sistemas de gerenciamento da empresa, tais como saúde, segurança, qualidade, finanças e planejamento.

\section{REFERENCIAIS TEÓRICOS}

\subsection{Passivo Ambiental}

Considera-se Passivo Ambiental toda a ocorrência de (IBAMA, 2008):

- Falha na construção, restauração ou manutenção de rodovia, capaz de atuar como fator de dano ou de degradação ambiental à área de influência direta, ao corpo estradal ou ao usuário;

- Condições climáticas adversas ou causadas por terceiros, capaz de atuar como fator de dano ou de degradação ambiental à faixa de domínio da rodovia, ao corpo estradal ou ao usuário.

O Passivo Ambiental apresentado por redes viárias se limita e é constituído por externalidades geradas pela existência da rodovia sobre terceiros e por externalidades geradas por terceiros sobre a rodovia (embora os últimos sejam passivos gerados por terceiros, nem sempre eles podem ser identificados ou responsabilizados, obrigando o órgão rodoviário a assumi-lo em benefício da estrada e/ou de seus usuários). Como exemplos das externalidades que constituem - Passivo Ambiental podem ser citadas (IBAMA, 2008): a) Atividades de terceiros interferindo na operação da rodovia: a implantação de loteamentos marginais, cujas obras de terraplenagem, quase sempre executadas sem o controle técnico necessário, causam assoreamento na pista de rolamento e no sistema de drenagem;

b) Externalidades geradas pela rodovia, agindo sobre terceiros: uma caixa de empréstimo que, após o término das atividades exploratórias, não foi beneficiada por serviços de recuperação da área. Neste caso, o surgimento de erosões e consequentes assoreamentos poderão prejudicar além do corpo estradal, propriedades lindeiras (perda de pastagens e áreas agricultáveis).

\subsection{Imagens Tridimensionais}

Segundo Ribas, Ribas e Rodrigues-Junior (2015), a visão binocular resultante da posição alinhada dos olhos permite-nos observar um mesmo objeto a partir de dois pontos de vista ligeiramente diferentes. A visão tridimensional ou estereoscópica, por sua vez, possibilita orientarmo-nos e interagirmos dentro do espaço que nos cerca, e é particularmente otimizada para elementos situados até cerca de três metros dos nossos olhos. 


\subsection{Geolocalização}

Segundo Felipe e Dias (2015), Geolocalização é a identificação de localizações geográfica de um usuário coletadas a partir de um dispositivo de computação por meio de uma variedade de mecanismos de coleta de dados. Normalmente, a maioria dos serviços de geolocalização usa endereços de roteamento de rede ou dispositivos GPS, interno para determinar esse local.

\subsection{Sistemas Web}

Segundo Zaneti-Junior e Vidal (2015) A Tecnologia Web foi criada como forma de divulgar o conhecimento científico, mas tem sido utilizada também como mecanismo de acesso a vários tipos de sistemas de informação empresariais, assim como de comunicação entre eles, gerando diversas oportunidades de negócios para as organizações. Os Sistemas de Informação baseados na Tecnologia Web (SIW) possuem características que permitem supor que o seu desenvolvimento apresenta diferenças em relação ao de sistemas não-Web.

\section{METODOLOGIA}

O processo para elaboração de um Passivo Ambiental inicia-se com a coleta de informações do trecho (por exemplo, parte de uma rodovia) ao qual se deseja avaliar utilizando imagens panorâmicas com cobertura de 360․ Para a aquisição das imagens, é utilizado um sistema de coleta de imagens de alta resolução. O sistema de câmera de vídeo digital esférica LadyBug 3 possui seis câmeras de 5 MP que permitem que o sistema de vídeo tenha uma cobertura 360 esférica e com resolução de até $30 \mathrm{MP}$. A Figura 2 mostra a imagem da LadyBug 3 utilizada para captura das imagens utilizadas neste trabalho.

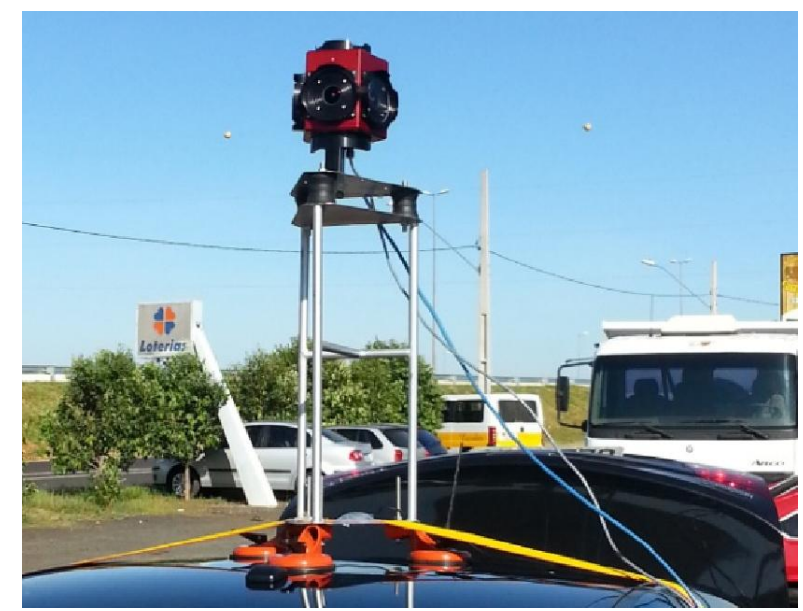

Figura 2. Sistema de câmera esférica LadyBug 3.

O trecho a ser avaliado é determinado pela coordenada dada em latitude e longitude do ponto Inicial, e pela latitude e longitude do ponto final. A Figura 3 mostra um exemplo de um trecho de rodovia com os pontos inicial e final. 


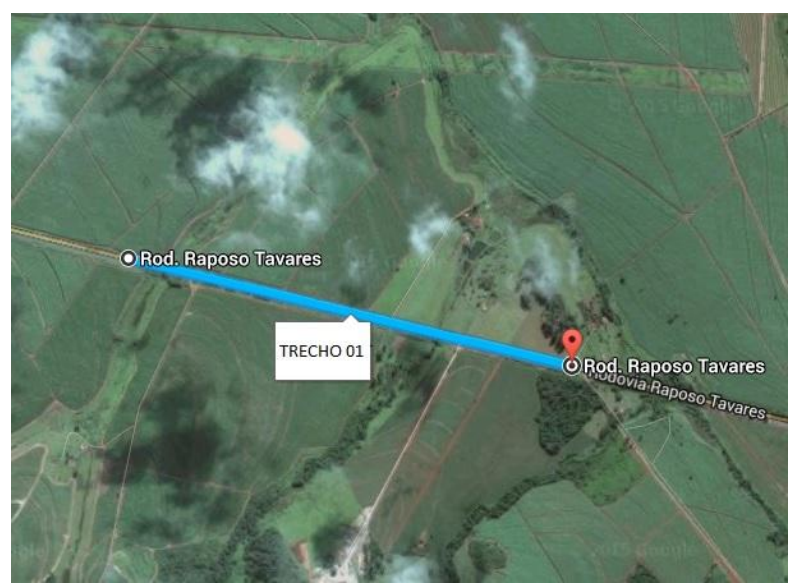

Figura 3. Exemplo de trecho de rodovia demarcado pelos pontos inicial e final.

Com o conhecimento do trecho e com o auxílio das imagens levantadas, e já inseridas no sistema, os passivos são identificados e georreferenciados. A aplicação desenvolvida neste trabalho, com acesso à internet, propicia ao usuário ir até o campo ou local do passivo ambiental, visualizar as imagens panorâmicas, e com auxílio de uma base 2D realizar o registro dos dados cadastrais dos danos ambientais. $\mathrm{O}$ sistema também permite que o usuário registre imagens fotográficas direcionadas ao dano ambiental. Finalizado o laudo, o laudista poderá gerar relatórios a partir dos dados registrados (informações do passivo ambiental, imagens 2D e 360, e georreferenciamento). A partir do laudo e relatórios que podem ser gerados pelo sistema desenvolvido, especialistas poderão observar as imagens atualizadas e tomar decisões para reduzir o impacto.

O sistema também auxilia no controle de serviços realizados em cada trecho, assim como o valor por cada unidade de medida e o valor total do serviço. Para se ter o controle conciso, o laudista deverá informar um tipo de serviço (os tipos de serviço serão précadastrados no sistema, onde o responsável pelo cadastro deverá informar sua descrição, sua unidade de medida e o valor por unidade como mostra a Figura 4.

\section{CADASTRO DE TIPOS DE SERVIÇO}

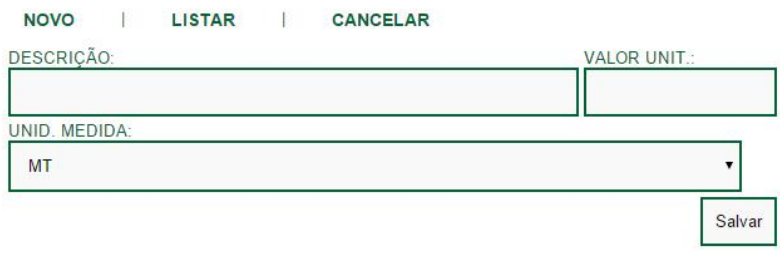

Figura 4. Cadastro de Tipos de Serviço

A Figura 5 mostra uma tela do sistema com o preenchimento dos serviços a serem realizados.

\section{CADASTRO DE SERVIÇOS - PASSIVO AMBIENTAL}

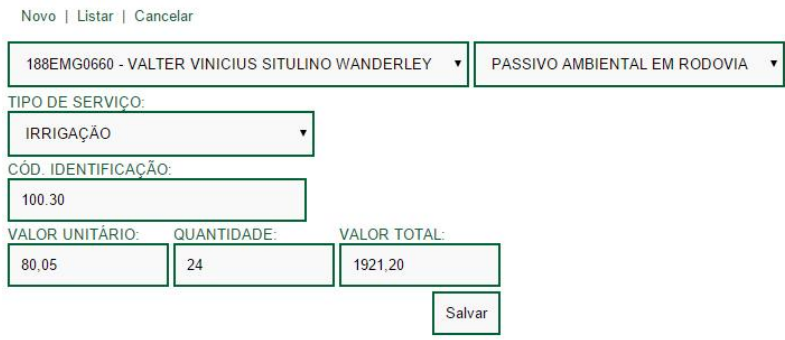

Figura 5. Preenchimento dos serviços a serem realizados.

A Figura 6 mostra uma tela do sistema contendo uma listagem de serviços a serem realizados. 
CADASTRO DE SERVIÇOS - PASSIVO AMBIENTAL

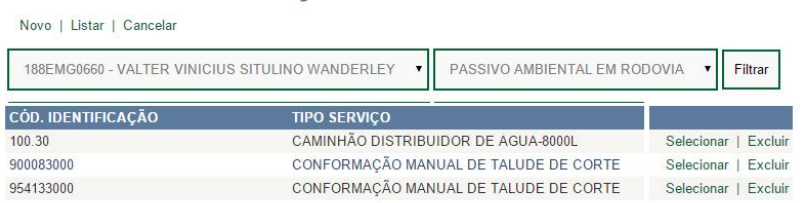

Figura 6. Listagem dos serviços a serem realizados.

Após estas informações estarem registradas no sistema, o laudista ou algum usuário do sistema poderá emitir relatórios pertinentes aos valores envolvidos e aos serviços realizados.

Os relatórios de serviços realizados, também podem ser utilizados para uma avaliação ou tomada de decisão em uma determinada região, ou, em alguns casos, em recorrência de dano no mesmo trecho. A Figura 7 mostra um relatório de serviços a serem realizados em um determinado trecho.

\section{RELATÓRIO DE SERVIÇOS}

\section{INFORMAÇÔES}

\begin{tabular}{|c|c|c|c|c|c|}
\hline \multicolumn{6}{|c|}{$\begin{array}{l}\text { Trecho: } \\
\text { 188EMG0660 - SIMPLES }\end{array}$} \\
\hline \multicolumn{6}{|c|}{$\begin{array}{l}\text { Solicitante: } \\
\text { VALTER VINICIUS SITULINO WANDERLEY }\end{array}$} \\
\hline \multicolumn{6}{|c|}{$\begin{array}{l}\text { Data: } \\
14 / 06 / 2015\end{array}$} \\
\hline \multicolumn{6}{|c|}{$\begin{array}{l}\text { Descrição: } \\
\text { PASSIVO AMBIENTAL EM RODOVIA }\end{array}$} \\
\hline $\begin{array}{l}\text { Posição: } \\
\text { DIR }\end{array}$ & $\begin{array}{l}\text { Latitude: } \\
-183046,5\end{array}$ & $\begin{array}{l}\text { Longitude: } \\
-470921,8\end{array}$ & $\begin{array}{l}\text { CRG: } \\
18\end{array}$ & $\begin{array}{l}\text { KM: } \\
2,70\end{array}$ & \\
\hline $\begin{array}{l}\text { Lado: } \\
\text { DIREITO }\end{array}$ & $\begin{array}{l}\text { Comprimento: } \\
200,00\end{array}$ & $\begin{array}{l}\text { Largura: } \\
20,00\end{array}$ & $\begin{array}{l}\text { Altura: } \\
8,00\end{array}$ & & \\
\hline \multicolumn{6}{|c|}{ Tipo de Serviço } \\
\hline 100.30 & \multicolumn{2}{|c|}{ CAMINHÃO DISTRIBUIDOR DE AGUA-8000L HRS } & $\mathrm{R} \$ 80,05$ & 24,00 & $\mathrm{R} \$ 1.921,20$ \\
\hline 900083000 & \multicolumn{2}{|c|}{ CONFORMAÇÃO MANUAL DE TALUDE DE CORTE M2 } & $\mathrm{R} \$ 1,65$ & 132,00 & $\mathrm{R} \$ 217,80$ \\
\hline \multirow[t]{2}{*}{954133000} & \multirow{2}{*}{\multicolumn{2}{|c|}{ CONFORMAÇÃO MANUAL DE TALUDE DE CORTE M2 }} & $\mathrm{R} \$ 1,49$ & 132,00 & R\$ 196,68 \\
\hline & & & & Valor Total: & $R \$ 2.335,68$ \\
\hline
\end{tabular}

Figura 7. Relatório de Serviços a serem realizados.

Na Figura 8 é apresentado um diagrama de processos para a elaboração de um Laudo de Passivo Ambiental. 


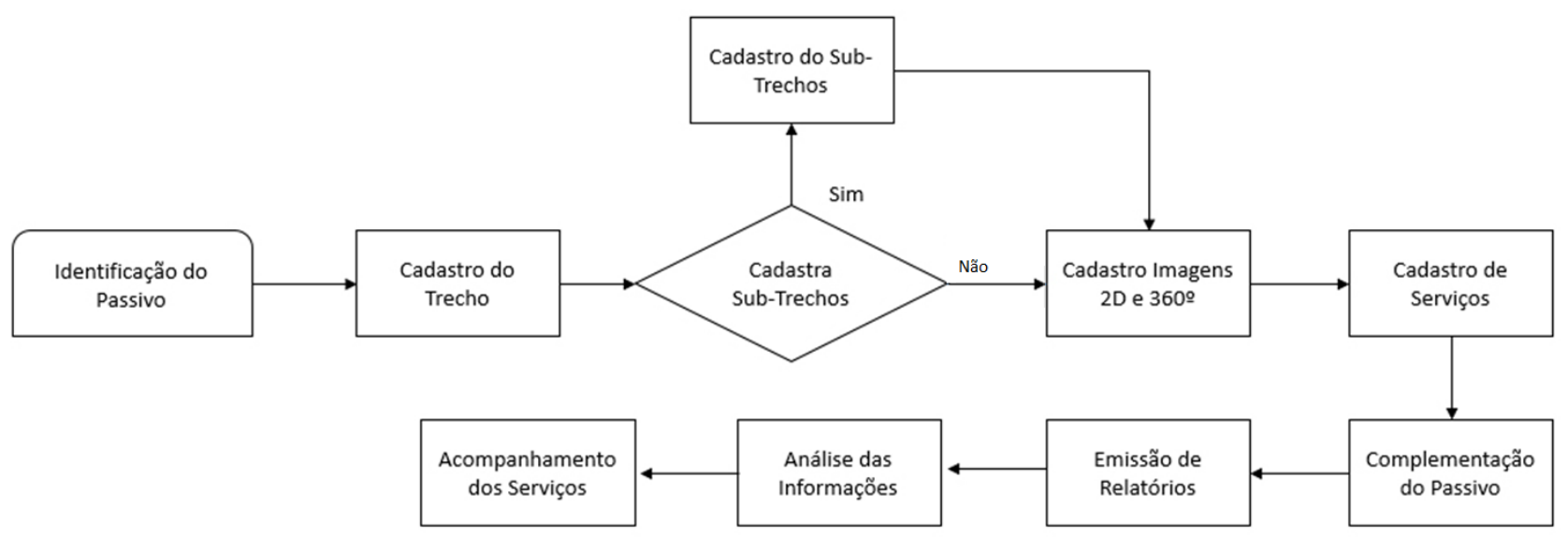

Figura 8. Diagrama de processos para a elaboração de Laudo de Passivo Ambiental.

O sistema foi desenvolvido utilizando conceitos de POO (Programação Orientada a Objetos) utilizando a linguagem de programação C\#. A Figura 9 mostra o diagrama de classes idealizado e modelado para o desenvolvimento do sistema. 


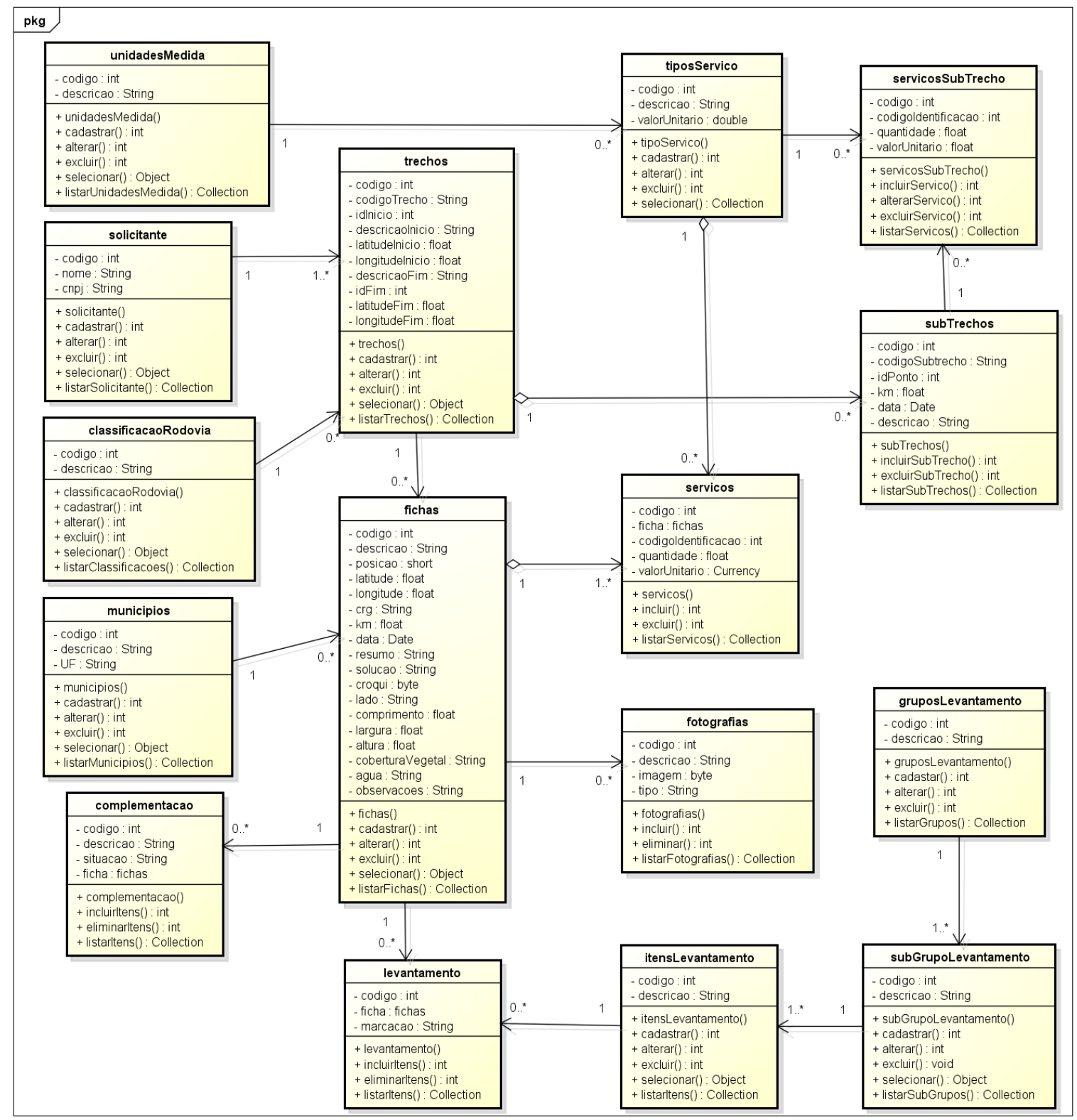

Figura 9. Diagrama de classes utilizadas no sistema.

Todos os dados do sistema são registrados em uma base dados SQL Server 2008. A Figura 10 mostra a estrutura de dados utilizada para armazenamento das informações geradas pelo sistema. A tabela "SOLICITANTE" é responsável por armazenar informações sobre os solicitantes de laudos de passivo ambiental; a tabela "TRECHO_PASSIVO" contém dados sobre o trecho a ser avaliado, e caso este trecho seja divido em trechos menores as informações serão armazenadas na tabela "SUBTRECHOS". Devido ao alto número de nomes de municípios, tipos de serviço, nomenclaturas de unidades de medida e nomenclaturas de classificação de rodovias, foram criadas tabelas para armazenar estas informações: "TIPOS_SERVICO”, "UNIDADE_MEDIDA", "CLASSIFICACAO_RODOVIA" e 
"MUNICIPIOS". A tabela "FICHAS_PASSIVO" é responsável pelas informações da ficha como identificação da ficha, resumo dos problemas levantados e suas soluções, todas as informações de serviços a serem realizados são armazenadas na tabela "SERVICOS", as imagens $2 \mathrm{D}$ e 360 o coletadas durante $\mathrm{O}$ levantamento do Laudo do Passivo serão armazenadas na tabela "FOTOGRAFIAS". As tabelas “COMPLEMENTACAO", "FICHAS_ITENS", "ITENS_COMPLEMENTO", "SUBGRUPO_COMPLEMENTO", “GRUPO_COMPLEMENTO” são responsáveis por armazenar as informações de complementação da ficha, ou seja, registro de informações sobre o panorama geral dos passivos ambientais existentes em uma determinada rodovia, contendo as informações de identificação da rodovia correspondente ao quadro geral dos passivos.

Para que o sistema possa atender as necessidades de um laudo de Passivo
Ambiental, foram implementadas algumas funcionalidades: Inclusão dos dados dos passivos ambientais; Visualização dos trechos por meio do Google Maps (2015); Visualização de imagens 360ํㅡ utilizando o plug-in Pannellum (PANNELLUM.ORG, 2014). As coordenadas (latitude inicial, longitude inicial, latitude final e longitude final) informadas pelo laudista servirão para se ter uma visão $2 \mathrm{D}$ da região do trecho do Passivo Ambiental. Essa visualização é obtida utilizando o Plug-in para visualização de mapas Google Maps (2015). Em cada trecho cadastrado o sistema disponibilizará um link com o rótulo "visualizar mapa", em que, ao acessar essa opção é aberta uma nova janela do navegador para o usuário visualizar o trecho selecionado. A Figura 11 mostra uma listagem de fichas cadastradas para um determinado trecho, nessa listagem é possível visualizar o link para o usuário acessar e visualizar o trecho em um mapa 2D. 


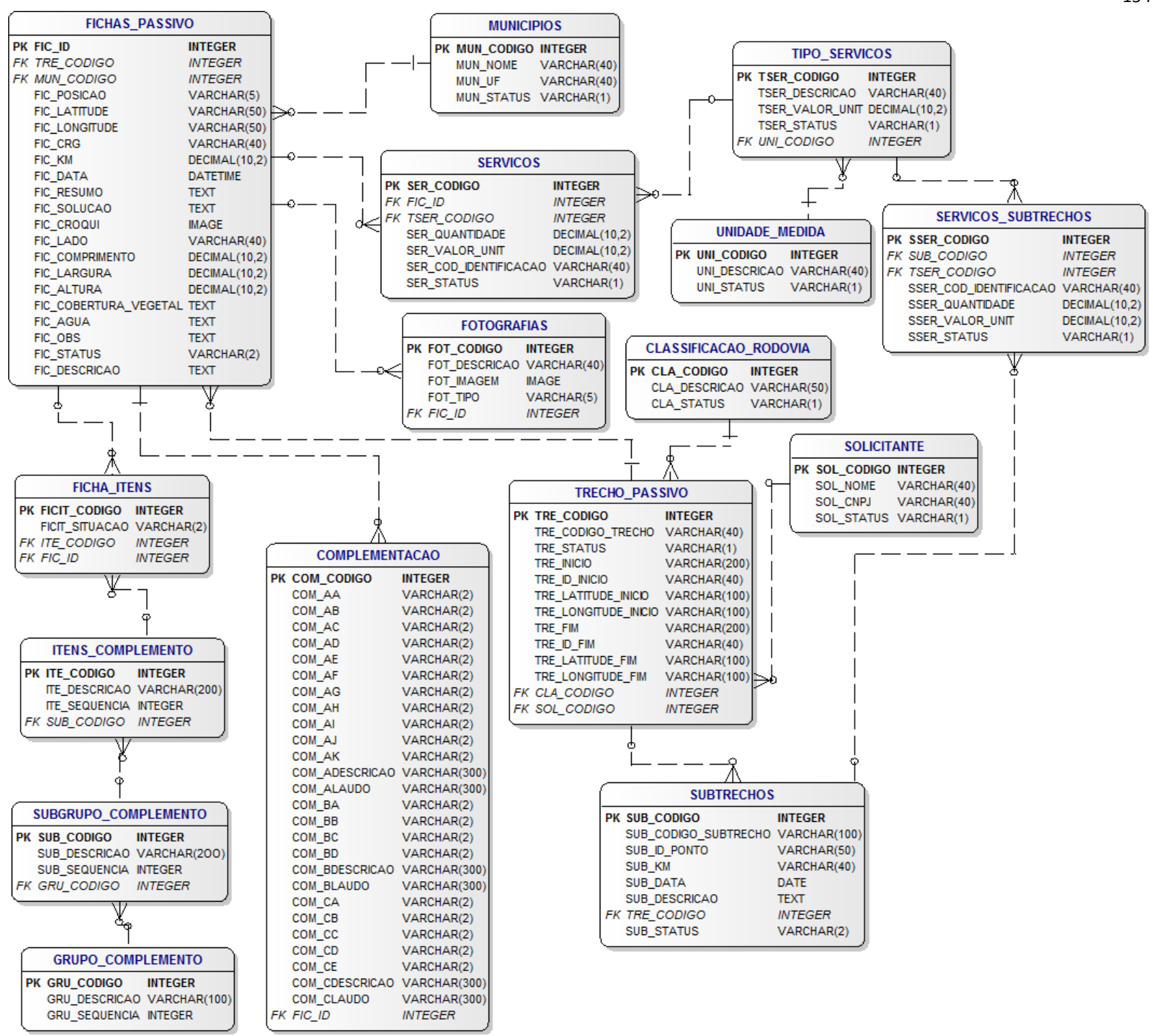

Figura 10. Diagrama do Banco de Dados e estrutura de tabelas.

\section{CADASTRO DE FICHAS - PASSIVO AMBIENTAL}

Novo | Listar | Cancelar

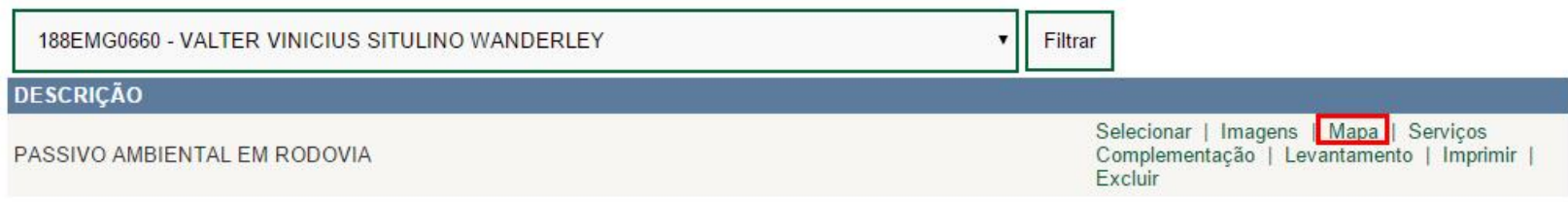

Figura 11. Listagem de fichas cadastradas com link para visualização no mapa.

A Figura 12 mostra a visualização do

local do passivo no mapa após o usuário ter

acessado o link da Figura 11. 


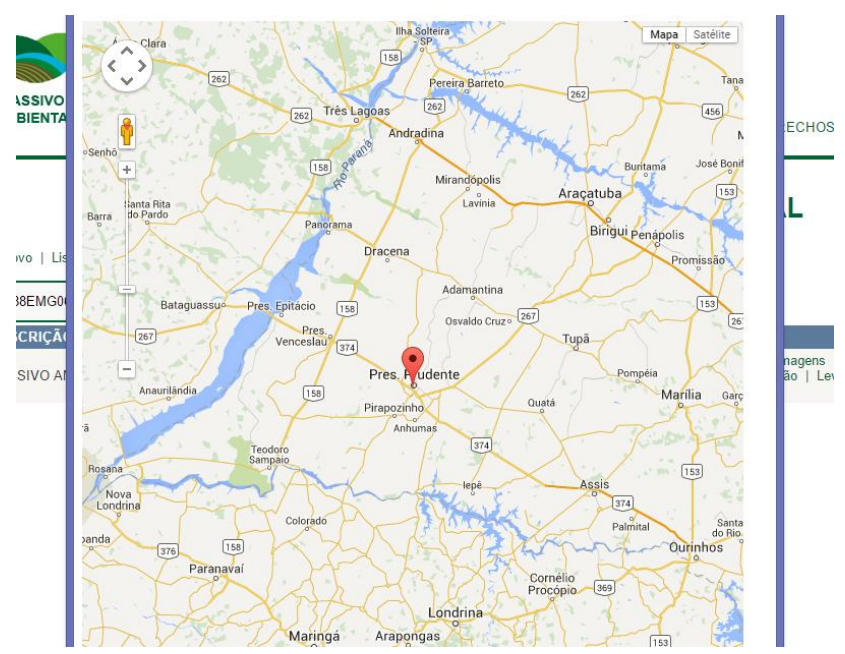

Figura 12. Visualização no mapa de trecho selecionado.

Todas as imagens obtidas do local pela câmera LadyBug 3 poderão ser visualizadas no sistema no formato 360을 para que a visualização em 360 으 possa ocorrer no sistema foi utilizado o plug-in de visualização $\quad 360$ 은 $\quad$ Pannellum (PANNELLUM.ORG, 2015). Esse plug-in tem alguns recursos de navegação entre os pontos da imagem, zoom em um determinado ponto da imagem, recursos esses que proporcionam ao usuário do sistema imergir no local do passivo mesmo que estando distante. O plug-in Pannellum tem como base a programação Java Script, sendo um visualizador livre e de código aberto para a Web. Ele foi construído utilizando as tecnologias HTML5, CSS3, Java Script e WebGL.

WebGL (2015) é um padrão para renderizar gráficos em qualquer navegador compatível, sem a necessidade de plug-ins adicionais. O WebGL é integrado completamente em todos os padrões da Web do navegador, permitindo o uso acelerado de processamento de imagens e efeitos gráficos processado pela GPU do computador. Os elementos do WebGL podem ser incorporados a outros elementos HTML e compostos com outras partes da página.

A Figura 13 mostra a imagem no formato original obtido através da câmera Lady Bug 3. A Figura 14 e Figura 15 mostram a imagem da Figura 13 exibida em dois pontos de vista diferentes utilizando o plug-in Pannellum.

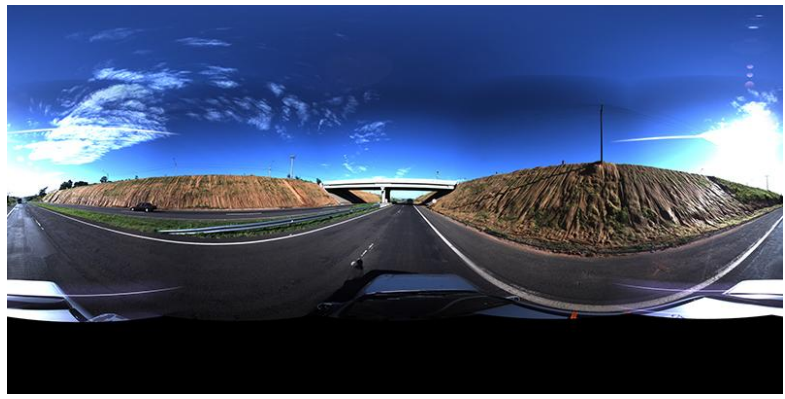

Figura 13. Imagem no formato original da câmera LadyBug 3.

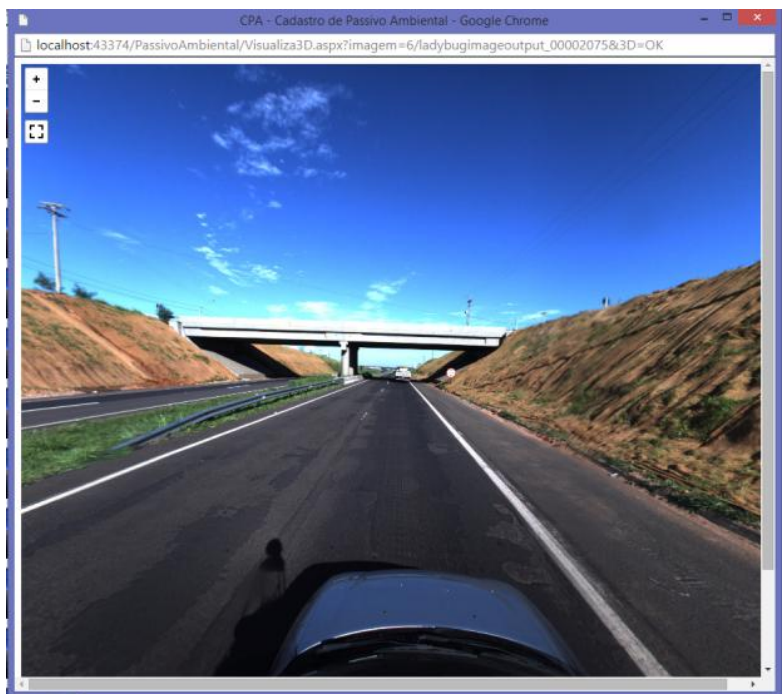

Figura 14. Imagem da câmera Ladybug sendo visualizada pelo plug-in Pannelum. 


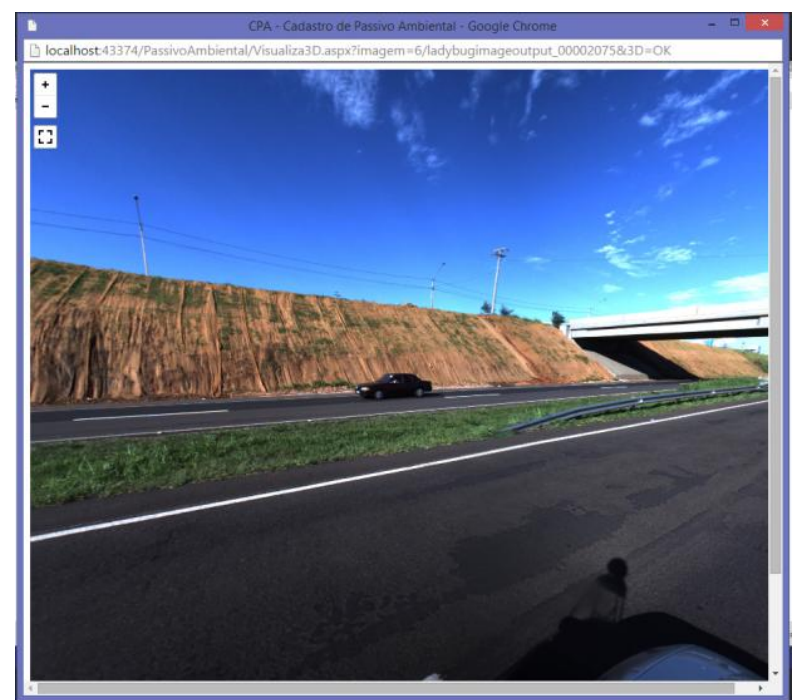

Figura 15. Visualização da imagem através do Plug-in Pannelum.

\section{EXPERIMENTOS E RESULTADOS}

O sistema para geração de Laudos de Passivo Ambiental tem como papel auxiliar na elaboração de laudos, manter histórico de serviços realizados, custos de cada serviço e também a posição exata do trecho a partir de sua latitude e longitude. O sistema também auxilia por meio de navegação e visualização de fotos tridimensionais a avaliação e tomada de decisão à distância onde se reduz o custo com viagens, hospedagem etc.

Cada laudo é composto por um trecho principal onde dele tem-se o ponto inicial e o ponto final (latitude e longitude inicial, latitude e longitude final), podendo este trecho ser dividido em sub-trechos, sendo que para cada sub-trechos poderá ser realizado diferentes tipos de serviços.

Como experimento, foi realizado um laudo de um passivo ambiental nas coordenadas latitude -22.122643 e longitude -51.4360585 descrevendo uma área sem cobertura vegetal nas margens de uma rodovia movimentada.

O laudista detectou que a área no local existia uma área de solo exposto em talude de corte no lado direito, com pequenos escorregamentos onde não oferecia risco ao tráfego. Porém oferecia risco ao ambiente pela ausência de cobertura vegetal. Para sua solução foi determinado realizar conformação manual da área $\mathrm{e}$ aplicar hidro-semeadura com manta vegetal, não sendo necessários serviços adicionais. 0 serviço de hidro-semeadura compõe-se de:

- Caminhão distribuidor de agua-8000Icompleto com barra irrigador e moto bomba;

- Conformação manual de talude de corte;

- Manta vegetal c/ hidro-semeadura. Após 0 preenchimento das informações no sistema desenvolvido neste trabalho obteve-se o resultado conforme a Figuras 16. Nessa figura pode-se visualizar uma Ficha de Cadastro de Passivo Ambiental contendo as informações cadastrais desse passivo, localização, resumo, solução adotada, croqui, fotografias e serviços realizados. 


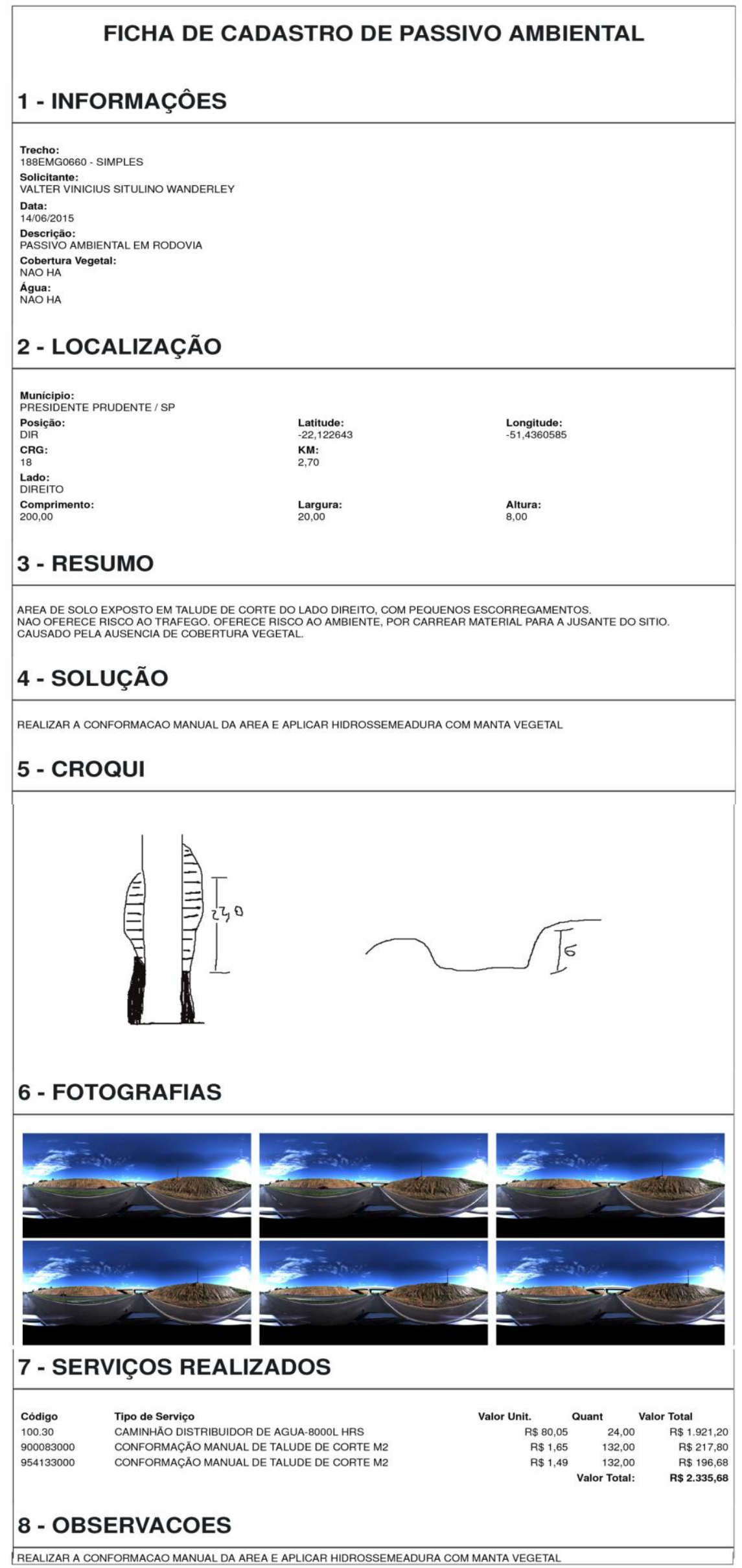

Figura 16. Laudo de um passivo Ambiental 
6 CONSIDERAÇÕES FINAIS

Segundo Kraemer (2008) a

identificação do passivo ambiental está sendo muito utilizada em avaliações para negociações de empresas e em privatizações, pois a responsabilidade e a obrigação da restauração ambiental podem recair sobre os novos proprietários. O passivo funciona como um elemento de decisão no sentido de identificar, avaliar e quantificar posições, custos e gastos ambientais potenciais que precisam ser atendidos a curto, médio e a longo prazo.

O cuidado que se há de ter com o passivo ambiental não está restrito ao empresário ou industrial, mas atinge o cidadão comum no seu cotidiano. De acordo com Jacometo (2004), a grande dificuldade que a ciência encontra é como mensurar um passivo ambiental. As clássicas perguntas que se fazem para chegar a uma resposta eficiente são: "Quanto o ser humano estaria disposto a pagar para ter a natureza preservada? Quanto vale a natureza?".

Por meio do estudo realizado, este trabalho contribuiu com uma solução de software onde se é capaz de reunir informações de campo, imagens fotográficas e tridimensionais, geolocalização, serviços necessários para reparos do passivo. Porém, não bastaria ter somente as informações, teria que ter um modelo padrão para emitir um laudo, e, através de estudos e captação de diversos modelos de laudo, foi proposto um modelo final para emissão de um Laudo de Passivo Ambiental apresentado neste trabalho.

\section{REFERÊNCIAS}

ALVES, P.; GONTIJO, G. A. S.; JUNIOR, A. Z. R. Análise do transporte rodoviário de produtos perigosos no estado de São Paulo suas consequências no meio ambiente. In: CONGRESSO DE MEIO AMBIENTE DA AUGM, 6. Anais... São Carlos, 2009.

ALMEIDA, F. $\mathbf{O}$ bom negócio da sustentabilidade. Rio de Janeiro: Nova Fronteira, 2002.

CETESB. Companhia de Tecnologia e Saneamento Ambiental. Relatório de estatísticas de atendimentos a acidentes ambientais. 2009.

COELHO, L. Impactos ambientais de rodovias. Disponível em: $<$ http://rodoviasverdes.ufsc.br/files/2010/04 /impactos-ambientais.pdf>. Acesso em: 20 mar. 2014.

FELIPE, H. L.; DIAS, J. W. Aplicações baseadas em geolocalização. Disponível em: http://web.unipar.br/ seinpar/2014/artigos/ graduacao/Heitor_Felipe.pdf. Acesso em: 22 jun. 2015.

GALLIS, R. B. A.; OLIVEIRA, R. A.; SILVA, J. F. C. Aplicação da unidade móvel de mapeamento digital para construir um banco de imagens georreferenciados. Revista de Iniciação Científica , v.2, p.212 - 221, 2000.

GALLIS, R. B. A.; SILVA, J. F. C.; CAMARGO, P. O. Mapeamento Móvel no Brasil: Resultados obtidos com a utilização da Unidade Móvel de Mapeamento Digital. In: SIMPÓSIO BRASILEIRO DE GEOMÁTICA. Anais... Presidente Prudente, 2002. 
GALLIS, R. B. A.; BARBOSA, R. L.; HIRAGA, A. KA. Integração entre Imagens Panorâmicas 360 ㅇ Terrestres e Imagens Orbitais de Alta Resolução no apoio a levantamento de Passivos Ambientais e Locais Propícios a Impactos Ambientais em Rodovias. In: COLÓQUIO BRASILEIRO DE CIÊNCIAS GEODÉSICAS, 8. Anais... Curitiba, 1 a 4 de dez., 2013.

Google Maps JavaScript API V3 Reference. Disponível em: https://developers.google.com/maps/docum entation/javascript/reference?csw=1. Acesso em: 21 maio 2015.

IBAMA. Estudo de impacto ambiental. v. 4, ago., 2008. Disponível em: <http://licenciamento.ibama.gov.br/Rodovia s/BR\%20317\%20Boca\%20do\%20Acre/EIA/Ca pitulo\%205\%20-

\%20Diagn\%F3stico\%20Ambiental\%20-

\%205.4\%20Passivos\% 20Ambientais.pdf>. Acesso em: 15 mar. 2014.

JACOMETO, M. A. Passivo ambiental: conceito moderno, velhas práticas. Disponível em: http://www.ambientebrasil.com.br. Acesso em: 08 jun. 2015.

KRAEMER, M. E. P. Passivo ambiental. 2008. Disponível em: http://www.amda.org.br/imgs/up/Artigo_21. pdf. Acessado em 08 jun. 2015.

JOHR, H. O verde é negócio. 3. ed. São Paulo: Saraiva, 1994.

LONGHITANO, G. A. VANTs para sensoriamento remoto: Aplicabilidade na avaliação e monitoramento de impactos ambientais causados por acidentes com cargas perigosas. 2010. 148f. Dissertação (Mestrado) - Escola Politécnica da Universidade de São Paulo. Departamento de Transportes.
PANNELLUM.ORG. Disponível em: https://pannellum.org/. Acesso em: 20 abr. 2014.

RIBAS, G. C.; RIBAS, E. C.; RODRIGUESJUNIOR, A. J. 0 cérebro, a visão tridimensional, e as técnicas de obtenção de imagens estereoscópicas. Disponível em: https://www.google.com.br/url?sa=t\&rct=j\& $q=\& e s r c=s \&$ source $=$ web\& $c d=15 \& v e d=0 C D Q$ QFjAEOAo\&url=http\%3A\%2F\%2Fwww.revista s.usp.br\%2Frevistadc\%2Farticle\%2Fdownload \%2F59218\%2F62233\&ei=VayIVeXOFoeyggTjt 6OgCw\&usg=AFQjCNHbD5LmTvNds_beQW9 ZR4DKQnI22Q\&bvm=bv.96339352,d.cWw\&c $\mathrm{ad}=\mathrm{rja}$. Acesso em: 22 jun. 2015.

RIBEIRO, R. Íntegra: regras do Ibama para a licença ambiental em estradas. 28 de março, $2010 . \quad$ Disponível em: <http://www.observatorioeco.com.br/integr a-regras-do-ibama-para-a-licenca-ambientalem-estradas/>. Acesso em: 18 mar. 2014.

SILVA, J. F. C.; CAMARGO, P. O.; GALLIS, R. B. A. Development of a low-cost mobile mapping system: a South American experience. Photogrammetric Record, v. 18, n. 101, p.5-26, 2003. http://dx.doi.org/10.1111/0031-868X.t01-100004

SILVA, J. F. C.; OLIVEIRA, R. A.; GALLIS, R. B. A. Georreferenced road image database. In: INTERNATIONAL SYMPOSIUM ON MOBILE MAPPING TECHNOLOGY, 3, Cairo. Proceedings... International Archives, ISPRS, CD-ROM, 8p. 2001a.

SILVA, J. F. C. et al. Mapeamento de ruas com um sistema móvel de mapeamento digital. Revista Brasileira de Cartografia, v.53, p.82 91, 2001b.

TINOCO, J. E. P. Ecologia, meio ambiente e contabilidade. Revista Brasileira de Contabilidade, Brasília, ano 23 no 89, p. 2431, nov 1994. 
TINOCO, J. E. P.; KRAEMER, M. E. P. Contabilidade e gestão ambiental. 2. ed. São Paulo: Atlas, 2008.

TOTH, C. Mapping with a mobile image acquisition system. Geolnfo System, 1995. p. 35-37.

WEBGL. O que é WebGL. Disponível em: https://helpx.adobe.com/br/flash/using/crea ting-publishing-webgl-document.html. Acesso em 15 maio 2015.
ZANETI-JUNIOR, L. A.; VIDAL, A. G. R. Construção de sistemas de informação baseados na Tecnologia Web. Disponível em: https://www.google.com.br/url?sa=t\&rct=j\& $q=\& e s r c=s \&$ source $=$ web\& $c d=1$ \&ved $=0 C B 4 Q F$ jAA\&url=http\%3A\%2F\%2Fwww.rausp.usp.br \%2Fdownload.asp\%3Ffile\%3DV4103232.pdf\& ei=ZcN1VcjhLIz7gwT1hIKACA\&usg=AFQjCNGZ 4qx281yfP_dlcH5nkUTT54vdQA\&bvm=bv.95 039771,d.eXY\&cad=rja - Acessado em 21 de maio de 2015. 